\title{
INCLUSÃO DA PESSOA COM DEFICIÊNCIA NO ENSINO SUPERIOR: UM ESTUDO DA PRODUÇÃO ACADÊMICA NA ÁREA DA EDUCAÇÃO
}

\author{
INCLUSION OF PEOPLE WITH DISABILITIES IN HIGHER EDUCATION: A STUDY \\ OF ACADEMIC PRODUCTION IN EDUCATION AREA
}

\author{
MENDES, Cleberson de Lima \\ cdelimamendes@gmail.com \\ UNIVILLE - Universidade da Região de Joinville \\ RIBEIRO, Sonia Maria \\ soniaproesa@gmail.com \\ UNIVILLE - Universidade da Região de Joinville
}

\begin{abstract}
RESUMO Este artigo apresenta um mapeamento das dissertações e teses nos Programas de Pós-Graduação em Educação (PPGE) do período de 2007 a 2015 no âmbito da inclusão de estudantes com deficiência no ensino superior, visando colaborar, dando continuidade, com os resultados apresentados no balanço de produções realizado por Bueno (2013) entre 1987 e 2006. Para tal, fez-se uma investigação nas bases de dados da Biblioteca Digital Brasileira de Teses e Dissertações (BDTD) e no Banco de Teses da Coordenação de Aperfeiçoamento de Pessoal de Nível Superior (Capes). $\mathrm{Na}$ análise das publicações foram catalogadas as seguintes informações: título, instituição, titulação, ano de defesa, objetivo, metodologia, instrumento de coleta de dados e abordagem metodológica para análise dos dados. Os resultados obtidos apontaram um aumento significativo no número de publicações e uma ampliação dos temas abordados nas dissertações e teses. As pesquisas baseiam-se na abordagem qualitativa, e a maioria caracterizouse pelo estudo de caso. Em relação à metodologia, prevaleceram as entrevistas na coleta de dados e a análise de conteúdo como instrumento para o tratamento dessas informações.
\end{abstract}

Palavras-chave: Ensino superior. Estado do conhecimento. Pessoas com deficiência.

ABSTRACT This article aims to present a mapping of dissertations and theses in Education Postgraduate Programs from 2007 to 2015 in the context of the inclusion of students with disabilities in higher education, with the purpose to collaborate, by continuing, with the results presented in Bueno's (2013) academic production review from 1987 to 2006. To this end, an investigation was conducted in Brazilian Digital Library of Theses and Dissertations (BDTD) and the Theses Database of Higher Education Personnel Improvement Coordination (CAPES). In the publications' analysis, the following information were cataloged: title, institution, degree, 
publication date, study goal, methodology, data collection instrument and methodological approach for data analysis. Results showed a significant increase in the number of publications and an expansion of the topics addressed in dissertations and theses. The researches were based on a qualitative approach and mostly characterized by case studies. Regarding methodology, interviews and content analysis prevailed in data collection and analysis, respectively.

Keywords: Higher education. People with disabilities. State of knowlegde.

\section{INTRODUÇÃO}

A década de 1990 representa um período histórico significativo para o movimento reconhecido como educação inclusiva, que visa garantir às pessoas com necessidades especiais, entre elas aquelas com deficiência, o direito à educação em instituições de ensino regular.

A partir desse período, houve um avanço na constituição de políticas públicas voltadas à educação das pessoas com deficiência, com ênfase inicialmente no sistema regular de ensino no nível da educação básica. Entre os documentos que objetivam assegurar esse direito aos brasileiros, destacam-se a Constituição Federal de 1988, a Lei de Diretrizes e Bases da Educação (LDB) n. 9.394/96, o Plano Nacional de Educação para Todos, de 2001, e a Política Nacional de Educação Especial na Perspectiva da Educação Inclusiva, de 2008.

Em relação ao ensino superior, além dos documentos já mencionados, outras políticas públicas voltadas de maneira específica para esse nível de ensino foram estruturadas com vistas à superação de um processo histórico marcado pela elitização e, por conseguinte, excludente para aqueles marginalizados socialmente, entre eles os oriundos de camadas de baixa renda, negros, mulheres e pessoas com deficiência.

O Brasil vem reiterando a importância da inclusão no ensino superior. Nesse sentido, órgãos do governo federal, especialmente o Ministério da Educação, têm realizado ações por meio de decretos, portarias e leis de elaboração de políticas públicas direcionadas à garantia do acesso e da permanência de acadêmicos com deficiência nas instituições de ensino superior.

Um dos primeiros documentos que nortearam o movimento de inclusão nessa modalidade de ensino foi o Aviso Circular n. 277/MEC/GM (BRASIL, 1996), de 8 de 
dezembro de 1996, requisitando aos reitores das universidades a execução de uma política adequada aos portadores de necessidades especiais. Além desse aviso, a Portaria n. 1.679 (BRASIL, 1999b) estabeleceu os requisitos de acessibilidade ao ensino de pessoas com deficiência, para instruir os processos de autorização e de reconhecimento de curso e credenciamento de instituições, revogada posteriormente pela Portaria n. 3.284 (BRASIL, 2003).

O Decreto n. 3.298 (BRASIL, 1999a), que regulamenta a Lei n. 7.853, de 24 de outubro de 1989, dispõe sobre a Política Nacional para a Integração da Pessoa Portadora de Deficiência, sinalizando na seção o acesso à educação e que as instituições de ensino superior devem oferecer adaptações de provas e apoio ao portador de deficiência.

Nos anos seguintes, o Parecer CNE/CEB n. 17, que fala sobre a organização dos sistemas de ensino para o atendimento ao aluno que apresenta necessidades educacionais especiais, apontou a educação especial como modalidade transversal a todos os níveis de ensino, incluindo a educação superior (BRASIL, 2001), e em 2004 o Decreto n. 5.296 regulamentou a Lei n. 10.048, que dispõe a respeito da prioridade de atendimento às pessoas com deficiência nos serviços públicos e em concessionárias de serviços públicos. Já a Lei n. 10.098 é concernente a normas gerais e critérios básicos para a promoção da acessibilidade das pessoas portadoras de deficiência ou com mobilidade reduzida (BRASIL, 2004).

Entre as políticas mais recentes que contribuem para 0 acesso e a permanência das pessoas com deficiência ao ensino superior, destacam-se o Programa Universidade para Todos (ProUni), instituído pela Lei n. 11.096, de 13 de janeiro de 2005 (BRASIL, 2005b), que reserva um percentual de bolsas às pessoas com deficiência em universidades privadas, desde que atendam aos critérios estabelecidos no programa; e o Programa de Acessibilidade na Educação Superior (Incluir), conforme Portaria Normativa n. 14, de 24 de abril de 2007 (BRASIL, 2007), que cita normas gerais e critérios básicos com o objetivo de incluir um número maior de pessoas com deficiência no meio acadêmico, tanto em instituições públicas como em particulares. Essas políticas constituem dois eixos relevantes para a inclusão das pessoas com deficiência ao ensino superior e modificam-se frequentemente, a fim de atender às especificidades desse movimento. 
Vale ressaltar que no ano de 2006, na cidade de Nova York, foi realizada a Convenção Internacional sobre os Direitos das Pessoas com Deficiência (BRASIL, 2009), cujo documento elaborado nesse encontro defende o direito de garantia de educação para todas as pessoas com deficiência, em consonância com a criação de políticas públicas que assegurem condições de permanência dos jovens na educação pública federal, atendendo às especificidades das pessoas com deficiência.

Em consonância com o documento da Convenção de Nova York, o Brasil, que é país signatário, instituiu mediante o Decreto n. 7.612 o Plano Nacional dos Direitos da Pessoa com Deficiência, que tem a finalidade de "promover, por meio da integração e articulação de políticas, programas e ações, o exercício pleno e equitativo dos direitos das pessoas com deficiência" (BRASIL, 2011), conhecido como Plano Viver sem Limite.

No que se refere a legislação e políticas públicas para pessoas com deficiência no ensino superior, o documento mais recente é o Plano Nacional de Educação, que entrou em vigor para o decênio 2014-2024 (BRASIL, 2014). Nesse documento, encontram-se estratégias específicas visando à inclusão de minorias, com ênfase na universalização e ampliação do acesso à educação e no atendimento em todos os níveis educacionais.

Considerando o exposto, o Brasil vem consolidando uma trajetória consistente no tocante à elaboração de leis e políticas voltadas à inclusão das pessoas com deficiência no ensino superior.

Nesse contexto, Moreira (2005a) afirma que as universidades devem ampliar o significado de sua função social e assegurar o direito à educação e à igualdade de oportunidades àqueles alunos que tradicionalmente não fazem parte de seu alunado, como é o caso dos estudantes com necessidades educacionais especiais, entre eles os acadêmicos com deficiência.

Refletindo sobre o processo histórico da educação inclusiva e diante da crescente expansão, universalização e incremento das políticas públicas para o acesso e a permanência dos estudantes com deficiência no ensino superior, teve início a pesquisa de dissertação de mestrado intitulada "O trabalho docente e a inclusão de estudantes com deficiência nos cursos de Licenciatura em Matemática", que visa compreender o trabalho docente na inclusão de estudantes com deficiência 
nos cursos de Licenciatura em Matemática das universidades do Sistema da Associação Catarinense das Fundações Educacionais (Acafe).

$O$ presente artigo representa um recorte desta dissertação e tem como objetivo apresentar o mapeamento das dissertações e teses dos Programas de PósGraduação em Educação (PPGE) do país no período de 2007 a 2015, no âmbito da inclusão de estudantes com deficiência no ensino superior. Objetivando compreender como essa temática tem sido abordada nas investigações, ocorreu uma busca por trabalhos publicados relacionados ao objeto de estudo. Nesse percurso encontramos "A educação inclusiva de crianças, jovens e adultos: avanços e desafios", relevante publicação na área de inclusão na qual Bueno (2013) apresenta um artigo com o balanço das produções sobre deficiência e ensino superior entre 1987 e 2006. Nesse estudo, o autor buscou analisar, sob diferentes ângulos, a relação entre alunos com deficiência e o ensino superior no Brasil, compreendendo um período de 15 anos da promulgação da Declaração de Salamanca.

Tendo em vista o propósito explicitado anteriormente, pretende-se responder aos seguintes questionamentos: Quais temas são recorrentes nos estudos envolvendo a inclusão de estudantes com deficiência no ensino superior? Quais as metodologias e técnicas de coleta de dados utilizadas nesses estudos? Houve inovação nas temáticas investigadas desde Bueno (2013)?

\section{METODOLOGIA}

Para a constituição do corpus de análise, utilizamos como lócus de investigação a base de dados da Biblioteca Digital Brasileira de Teses e Dissertações (BDTD) e o Banco de Teses e Dissertações da Coordenação de Aperfeiçoamento de Pessoal de Nível Superior (Capes). Foram selecionados os resumos das dissertações e teses, restringindo-se às publicações produzidas em PPGE entre 2007 e 2015, objetivando dar continuidade ao trabalho realizado por Bueno (2013) 1 .

\footnotetext{
${ }^{1}$ Bueno (2013) realizou o balanço apenas no Banco de Teses da Capes.
} 
Segundo André (2009), esses mapeamentos são fundamentais para acompanhar a constituição de uma área do conhecimento, porque revelam as temáticas que permanecem ao longo do tempo, assim como esmaecem os que despontam promissores e apontam as metodologias priorizadas pelos pesquisadores, fornecendo elementos importantes para aperfeiçoar a pesquisa num determinado campo do saber.

A escolha pela busca das produções na área da educação decorre por ser essa a área de conhecimento em que a pesquisa e os pesquisadores estão inseridos e, como sustenta Charlot (2006), se fazem necessários registrar a memória da pesquisa em educação e constituir um arquivo coletivo da pesquisa em educação, evitando a repetição de temáticas e metodologias, fornecendo pontos de apoio para aquilo que vem sendo produzido e identificando novos pontos de partida.

Para isso, foi realizado um levantamento nos bancos de dados, por meio dos seguintes descritores: "acadêmico com deficiência e ensino superior", "estudante com deficiência e ensino superior" e "pessoas com deficiência e ensino superior", refinando os resultados apenas na área da educação².

Os resumos pertinentes à temática foram analisados e catalogados em uma planilha de Excel com as seguintes informações: título, instituição, titulação, ano de defesa, objetivo, campo empírico de investigação, metodologia, instrumento de coleta de dados e abordagem metodológica para análise dos resultados. Quando esses dados não estavam disponíveis nos resumos, buscou-se o percurso metodológico das produções para identificação desses critérios.

\section{O QUE REVELAM OS DADOS DAS DISSERTAÇÕES E TESES}

No balanço das produções realizado por Bueno (2013), foram encontradas 32 publicações em PPGE em um intervalo de 20 anos. Em relação a esse dado, podemos dizer que houve o incremento de $28 \%$ nas publicações que envolvem a temática nessa área de conhecimento. Na BDTD e no Banco de Teses e

\footnotetext{
2 Esses descritores foram utilizados no singular e plural, já que se constataram discrepâncias nos resultados quando da comparação entre essa variação.
} 
Dissertações da Capes há 45 trabalhos tendo como pertinência o campo da inclusão de pessoas com deficiência no ensino superior.

Ainda no âmbito do aumento da produção científica, podemos considerar, como aponta Martins, Leite e Lacerda (2015), que as matrículas de pessoas com deficiência no ensino superior vêm aumentando, especialmente nas instituições públicas, uma possível consequência da implementação de programas do governo federal oriundos da gestão do presidente Luiz Inácio Lula da Silva, iniciada no ano de 2003, citadas na introdução deste artigo.

Os dados referentes às instituições precursoras desses estudos ainda se mantêm, e a maioria dos trabalhos foi produzida em instituições públicas federais (58\%). Na sequência, aparecem as instituições públicas estaduais, com $22 \%$, e depois as instituições comunitárias, com $13 \%$, enquanto as instituições particulares representam apenas $2 \%$ no âmbito de pesquisas na temática.

Em relação à distribuição por nível de titulação, o percentual manteve-se o mesmo registrado por Bueno (2013), com $86 \%$ das produções incidentes em dissertações de mestrado e $14 \%$ em teses de doutorado.

No que tange à distribuição regional, verificou-se que a Região Nordeste mantém a maior proporção das pesquisas, com 44\%, seguida da Região Sudeste, com $38 \%$. O Sul ficou com 16\%, e o Centro-Oeste, com $2 \%$. Em uma pesquisa realizada por Azevedo e Santos (2009), as regiões Nordeste e Sudeste concentram o maior número de cursos de pós-graduação no país, o que explica o maior percentual.

$\mathrm{Na}$ continuidade da investigação, após a análise de conteúdo dos resumos, organizaram-se as temáticas em sete categorias: trabalho docente e inclusão de acadêmicos com deficiência no ensino superior, políticas públicas de inclusão no ensino superior, políticas de inclusão institucional para pessoa com deficiência $(P C D)$, a $P C D$ no ensino superior, ingresso e permanência da $P c D$ no ensino superior, docente com deficiência no ensino superior e concepção de professores.

A seguir estão descritas as categorias e as temáticas abordadas nas pesquisas dos pós-graduandos.

$\mathrm{Na}$ categoria 1, trabalho docente e inclusão de acadêmicos com deficiência no ensino superior, foram reunidos cinco trabalhos. Para Duarte (2011), a formação docente - inicial e continuada -, a prática pedagógica, as condições e o processo de 
trabalho, entre outros são aspectos que envolvem o trabalho docente. As pesquisas que balizam essa categoria buscam compreender os desafios que perpassam a atividade docente na inclusão de estudantes com deficiência, analisando e revendo a prática docente diante desse desafio e na construção de saberes para atuar com alunos com deficiência.

No grupo políticas públicas de inclusão no ensino superior foram incluídas duas pesquisas que versam sobre as políticas públicas para inclusão de pessoas com deficiência nesse nível de escolarização. Uma das publicações discute o Programa de Apoio à Planos de Reestruturação e Expansão das Universidades Federais (Reuni) e a relação com o acesso das pessoas com deficiência no ensino superior, especificamente em uma instituição do nordeste do país, e a outra produção debate acerca da inclusão de alunos surdos no ensino superior, tratando das peculiaridades desse processo.

O baixo número de pesquisas nessa temática pode relacionar-se com o que apontam Duarte et al. (2013), situando que se tem documentado pouco quanto à inclusão de pessoas com deficiência no Brasil, dificultando a formulação de políticas públicas com ações que contemplem a educação inclusiva no ensino superior. Ainda, segundo os autores, o incremento de políticas públicas para as pessoas com deficiência no ensino superior é recente, visto que o aumento de matrículas desse grupo de pessoas consiste em movimento atual nesse nível de ensino.

$\mathrm{Na}$ categoria políticas de inclusão institucional para $P c D$, foram situados 11 trabalhos que focalizam estudos que permeiam a adoção de políticas institucionais para a permanência de estudantes com deficiência nas instituições de ensino superior. Os assuntos abordados nesses trabalhos perpassam por ações que estão constituídas nesses espaços para a inclusão de pessoas com deficiência, observância dos aspectos legais que norteiam as políticas institucionais, mas observamos que grande parte dos estudos nessa categoria se concentrou na investigação, na análise e no acompanhamento das políticas nas suas instituições. Moreira (2005b, p. 10) explica que a inclusão no ensino superior se efetivará se "investir na acessibilidade, na previsão e provisão de recursos materiais e humanos para esse alunado".

Nesse sentido, Valdés (2005) expõe a preocupação que o país vem adotando em relação à democratização do acesso e permanência na universidade a partir do 
desenvolvimento de uma política de educação superior que atenda as demandas dos grupos socialmente desfavorecidos, incluso neste contingente, as pessoas com deficiência. É necessário criar condições para que esse aluno permaneça e vivencie um processo educacional de qualidade. Assim, a elaboração de ações institucionais para as pessoas com deficiência está na criação de um ambiente educativo comprometido com o direito de aprender desses estudantes.

No grupo a $P c D$ no ensino superior, foram reunidas sete produções que têm como propósito investigar as trajetórias de estudantes com deficiência no ensino superior. Os temas recorrentes falam da história desses estudantes relativas à sua escolarização, na investigação das experiências vivenciadas no cotidiano no ambiente universitário buscando identificar as relações objetivas e subjetivas que contribuíram para o acesso e auxiliam na permanência desses estudantes nas instituições averiguadas. Duarte et al. (2013) ressaltam que a realização de estudos que visam ampliar as informações sobre a inclusão de pessoas com deficiência no meio educacional, bem como entender o processo de dificuldades, luta e superação desses estudantes até chegar ao ensino superior, tem sido importante para auxiliar os profissionais que estão envolvidos na luta pelo direito das pessoas com deficiência.

$\mathrm{Na}$ categoria ingresso e permanência da $P C D$ no ensino superior, que apresenta $\circ$ número mais alto de produções, têm-se 16 trabalhos. Neles encontramos como tema recorrente a acessibilidade, não se restringindo apenas à questão física e arquitetônica - barreira arquitetônica.

Nessas pesquisas, os autores buscaram avaliar as condições de acessibilidade arquitetônica na estrutura física das universidades. Para Manzini (2005), a acessibilidade é um caminho para a inclusão na universidade, segundo ele, faz-se necessário que a estrutura física e administrativa das instituições esteja relacionada às políticas inclusivas, refletindo atitude de luta contra a exclusão.

Alguns estudos investigaram a acessibilidade pedagógica de algumas instituições, com foco nas práticas pedagógicas e avaliativas, acesso a recursos tecnológicos em um ambiente de ensino a distância e programas de tutoria, por colaborarem com a permanência desses estudantes. Ainda nessa categoria, alguns trabalhos discutiram as condições oferecidas aos acadêmicos com deficiência no intuito de conhecer as condições de permanência e o desempenho dos acadêmicos 
com deficiência. Outro tema que se evidenciou nessa categoria se volta para a questão dos fatores afetivos e relacionais - barreiras atitudinais -, que contribuem para a prática educativa de estudantes com deficiência.

Ressaltamos que são recentes na história da universidade brasileira a democratização e a universalização do acesso ao ensino superior no país, este movimento somado a elaboração das políticas de inclusão implicando numa ressignificação desses espaços. Além das barreiras arquitetônicas, o preconceito em relação aos indivíduos com deficiência talvez seja um dos maiores desafios para a permanência das pessoas com deficiência no ensino superior. De acordo com Valdés (2006), as barreiras atitudinais são as reconhecidas como as mais fortes e intangíveis, "pois envolvem componentes cognitivos, afetivos e de conduta formados histórica e socialmente, que incluem desde fatores sociais como o estigma da deficiência e sua difícil diferenciação de doença".

$\mathrm{Na}$ categoria docente com deficiência no ensino superior, as pesquisas agrupadas aqui somam três produções que discutem a prática pedagógica, estabelecendo uma reflexão sobre a inclusão profissional perante a trajetória de escolarização e analisam os desafios dos docentes com deficiência no ensino superior. No que diz respeito a essa categoria, os pesquisadores evidenciaram a voz dos docentes com deficiência a fim de buscar indicativos referentes à experiência escolar e à inserção profissional desses sujeitos tendo em vista o êxito que tiveram.

Orlando e Caiado (2014), no artigo intitulado "Professores universitários com deficiência: trajetória escolar e conquista profissional", afirmam que as questões que envolvem a escolarização de pessoas com deficiência devem ser discutidas e refletidas no contexto da sociedade em que estão inseridas e dos sujeitos que as vivenciam, relacionando a trajetória de vida desses docentes e sua inserção profissional.

Já na categoria concepção de professores, identificamos apenas um trabalho, que buscou investigar as concepções de deficiência presentes nas representações dos professores, por meio de suas experiências materiais e simbólicas. A concepção de mundo, de sujeito e de sociedade está intimamente relacionada à que atribuímos às pessoas com deficiência. De acordo com Amaral (2001, p. 150), um dos caminhos para romper com as barreiras atitudinais: 
[...] é percebermos o que está se passando, para que possamos não eliminar preconceitos (objetivo impossível de ser atingido), mas reconhecêlos em nós e, então, elaborá-los para que não se interpolam em nossas relações vivas e pulsantes de cada dia.

Comparando tais dados com os de Bueno (2013), houve uma ampliação significativa nos temas abordados nas dissertações e teses. No período de 1987 a 2006, a maioria das pesquisas dedicava-se aos estudos dos processos de inclusão de estudantes com deficiência. A partir de 2006, a maior parte dos trabalhos averigua $o$ ingresso e a permanência dos estudantes no ensino superior.

Essa mudança pode ser fruto da implantação de políticas públicas datadas a partir de 2005 em diante, como o ProUni, o Programa Incluir, a Política Nacional de Educação Especial na Perspectiva da Educação Inclusiva e o Plano Nacional dos Direitos da Pessoa com Deficiência, que favorecem o acesso e definem ações para a permanência de estudantes com deficiência no ensino superior.

Outros temas comparados ao balanço realizado por Bueno (2013) se mantiveram na mesma proporção, como: concepção de professores, prática docente e apoio a alunos com deficiência (aqui inclusos na categoria ingresso e permanência de estudantes no ensino superior) e deficientes com formação superior, essa inserida na categoria docentes com deficiência no ensino superior.

No que concerne à área de Educação percebemos a temática referente às políticas públicas e ações institucionais para as pessoas com deficiência nas instituições de ensino superior, como propostas frequentes nos estudos realizados a partir de 2006, porém, ainda uma baixa produção voltada a temática do trabalho docente junto a esses acadêmicos, sendo este um tema inegavelmente desafiador e atual.

Estudos que abordam a trajetória das pessoas com deficiência no ensino superior também se mostraram significativos e podem ser compreendidos como um campo de pesquisa peculiar, pois, ao ir ao encontro das experiências vividas por esses sujeitos, durante sua trajetória na universidade, pode ser possível romper com alguns preconceitos em relação à pessoa com deficiência.

Diante o exposto, consideramos que os temas recorrentes nas pesquisas analisadas discutem o ingresso e a permanência de estudantes com deficiência; as políticas de inclusão institucional; bem como as experiências das pessoas com deficiência no ensino superior. Tais estudos materializam indicativos para o 
desenvolvimento de ações e políticas públicas educacionais que visam a garantia do direito das pessoas com deficiência a educação superior.

Quanto à metodologia, prevalecem os estudos de abordagem qualitativa, com $89 \%$, e os demais trabalhos inseridos na abordagem quantiqualitativa, com $11 \%$. Esses números equiparam-se com as reflexões de Bueno (2013), reflexões estas utilizadas como ponto de partida para as discussões deste trabalho.

Em relação ao tipo de pesquisa, $60 \%$ das produções analisadas informaram sua característica - 32\% apontaram ter realizado estudo de caso. Na sequência, apareceram as pesquisas do tipo exploratório e documental, com 9\%; a história de vida, com 6\%; e finalmente as pesquisas do tipo pesquisa-formação e etnográfica, ambas com $2 \%$ de participação. O restante das publicações, um total de $40 \%$, não informou a tipologia da pesquisa.

Segundo André (1995, p. 52), "a escolha de uma determinada forma de pesquisa depende antes de tudo da natureza do problema que se quer investigar e das questões específicas que estão sendo formuladas". Diante das variadas temáticas discutidas no âmbito da inclusão de pessoas com deficiência no ensino superior, justifica-se a escolha por diferentes tipos de pesquisa.

Em relação à incidência maior do estudo de caso, André (2013) relata que o conhecimento gerado pelo estudo de caso é diferente do de outros tipos de pesquisa, porque é mais concreto, mais contextualizado. Ainda, segundo ela, é o tipo de pesquisa que contribui para investigar fenômenos educativos no contexto natural. Então, no movimento de inclusão no ensino superior, ele pode auxiliar na compreensão do desenvolvimento desse fenômeno e na análise de como ocorre sua evolução em um determinado período.

Bueno (2013) não apontou o tipo de pesquisa escolhido pelos pesquisadores, porém investigou os procedimentos de coleta de dados. Segundo o autor, a entrevista era o instrumento de coleta de dados que predominava, com $42,5 \%$; na sequência vieram a análise documental, o questionário e a observação, para completar as ferramentas de coleta de dados.

Nesta investigação a situação não difere, pois a maioria dos trabalhos utiliza a entrevista como instrumento de coleta de dados, incidente em $77 \%$ dos trabalhos investigados. O questionário aparece com $37 \%$, seguido da análise documental, com $31 \%$; da observação, com 15\%; logo depois a pesquisa bibliográfica, com 13\%; e, 
por fim, outros métodos, com 22\% (sites, Facebook, registro fotográfico, diário de pesquisa, pesquisa de campo, videogravação, autoconfrontação simples).

Observa-se que pouco mais de $70 \%$ das pesquisas usam mais de um método para coleta de informações e alguns trabalhos, ainda que em menor quantidade, empregam recursos tecnológicos e redes sociais.

Como mencionado anteriormente, a escolha da técnica de pesquisa deve corresponder à natureza da pesquisa a ser investigada. Demo (2002) argumenta que o cuidado metodológico constitui um procedimento formativo dos mais indispensáveis, porque, além da reconstrução de procedimentos reprodutivos, a pesquisa busca marcar um campo político.

Pode-se afirmar que as entrevistas e a aplicação de questionários são os instrumentos de coleta de dados utilizados com frequência. Segundo Manzini (2012, p. 150), "a entrevista tem sido um procedimento de coleta de dados amplamente utilizado em pesquisa em ciências humanas" e segundo o autor, faz emergir as informações de forma mais livre e as respostas não estão condicionadas a uma padronização de alternativas. Ainda, alerta aos pesquisadores a se aterem aos cuidados metodológicos ao utilizar esse método na coleta de dados e na análise das informações.

Segundo May (2004), o uso de questionário apresenta algumas vantagens, dentre elas o baixo custo, a preservação do anonimato dos participantes, a liberdade de tempo para ser respondido, o fato de não haver interferências de pesquisadores diferentes e a possibilidade de alcançar um número grande de sujeitos, indicadores que podem favorecer a utilização desse instrumento nas pesquisas realizadas.

O último tópico investigado neste estudo, diz respeito às metodologias empregadas nas análises dos dados coletados nas produções realizadas, no qual identificou-se a predominância da análise de conteúdo, com $51 \%$. Segundo Franco (2012, p. 12), esse método trabalha com a palavra e parte da "mensagem (escrita ou oral), gestual, silenciosa, figurativa, documental ou diretamente provocada", visando interpretar e compreender o que expressam os seus conteúdos. Aproximadamente $35 \%$ dos trabalhos não explicitaram a técnica empregada na análise dos dados, e o restante divide-se proporcionalmente entre a análise do discurso, núcleos de significação, análise de sentidos e hipertexto. 


\section{CONSIDERAÇÕES FINAIS}

Como apresentado na introdução deste artigo, a partir dos anos 2000, houve um avanço significativo na elaboração de leis específicas e na estruturação de políticas públicas visando garantir o acesso e a permanência das pessoas com deficiência no ensino superior.

Em consonância com esse dado, os resultados do levantamento mostram que as produções sobre a inclusão de estudantes com deficiência no ensino superior se ampliaram significativamente de 2006 em diante, podendo esse fato estar relacionado com esses avanços legais.

A análise da produção acadêmica nos programas de pós-graduação do país apontou a ausência de pesquisas desenvolvidas nas regiões Norte e Centro-Oeste e revelou $\mathrm{o}$ interesse crescente dos pesquisadores pela temática que envolve 0 movimento de acesso e permanência das pessoas com deficiência nas instituições de ensino superior e as políticas institucionais que se preocupam com o ingresso e também com a permanência desses alunos.

Além disso, observou-se a preocupação da maioria dos pesquisadores com o rigor metodológico para o desenvolvimento das investigações e na constituição de um corpus de análise favorecendo na compreensão de como vem se constituindo esse movimento sob diferentes ângulos.

De modo geral, pode-se dizer que a inclusão de estudantes com deficiência, a partir das políticas educacionais, vem se constituindo de modo expressivo nas instituições de ensino superior do país. Assim sendo, faz-se necessário o desenvolvimento de pesquisas que possam contribuir para os avanços essenciais que auxiliarão não apenas em termos da educação como da inclusão social das pessoas com deficiência.

\section{CLEBERSON DE LIMA MENDES}

Mestrando em Educação no Programa de Mestrado em Educação da Universidade da Região de Joinville (UNIVILLE). Professor de Matemática na rede de ensino municipal de Joinville (SC). 


\section{SONIA MARIA RIBEIRO}

Doutora em Educação pela Universidade Metodista de Piracicaba - UNIMEP. Professora no Programa de Mestrado em Educação da Universidade da Região de Joinville (UNIVILLE).

\section{REFERÊNCIAS}

AMARAL, L. A. A diferença corporal na literatura: um convite a "segundas leituras". In: SILVA, S.; VIZIM, M. (Orgs.). Educação especial: múltiplas leituras e diferentes significados. Campinas: Mercado das Letras, 2001. p. 131-161.

ANDRÉ, M. E. D. A. de. A produção acadêmica sobre formação de professores: um estudo comparativo das dissertações e teses defendidas nos anos 1990 e 2000. Revista Brasileira de Pesquisa sobre Formação de Professores, v. 1, n. 1, ago./dez. 2009. Disponível em:

<http://formacaodocente.autenticaeditora.com.br/artigo/exibir/1/7/1>. Acesso em: 26 fev. 2016. Pedagógica).

Etnografia da prática escolar. Campinas: Papirus, 1995. (Série Prática

O que é um estudo de caso qualitativo em educação? Educação $e$ Contemporaneidade, Salvador, v. 22, n. 40, p. 95-103, jul./dez. 2013. Disponível em: $<$ revistas.uneb.br/index.php/faeeba/article/download/753/526>. Acesso em: 15 abr. 2016.

AZEVEDO, J. M. L. de; SANTOS, A. L. F. dos. A pós-graduação no Brasil, a pesquisa em educação e os estudos sobre a política educacional: os contornos da constituição de um campo acadêmico. Revista Brasileira de Educação, v. 14, n. 42, 2009.

BRASIL. Ministério da Educação. Aviso circular n. 277/MEC/GM. Brasília: MEC, 1996. Dirigido aos Reitores das IES, solicitando a execução adequada de uma política educacional dirigida aos portadores de necessidades especiais. Brasília, 1996.

Decreto n. 3.298, de 20 de dezembro de 1999. Regulamenta a Lei n. 7.853, de 24 de outubro de 1989, dispõe sobre a Política Nacional para a Integração da Pessoa Portadora de Deficiência, consolida as normas de proteção, e dá outras providências. 1999a. Diário Oficial da República Federativa do Brasil, Brasília, DF, n. 243, p. 10, 21 dez. 1999. Seção 1. 
Decreto n. 5.296, de 2 de dezembro de 2004. Regulamenta as Leis $\mathrm{n}$. $\overline{10.048}$, de 8 de novembro de 2000 , que dá prioridade de atendimento às pessoas que especifica, e 10.098, de 19 de dezembro de 2000, que estabelece normas gerais e critérios básicos para a promoção da acessibilidade das pessoas portadoras de deficiência ou com mobilidade reduzida, e dá outras providências. Diário Oficial da República Federativa do Brasil, Brasília, DF, n. 232, p. 5, 3 dez. 2004. Seção 1.

Decreto n. 6.949, de 25 de agosto de 2009. Promulga a Convenção Internacional sobre os Direitos das Pessoas com Deficiência e seu Protocolo Facultativo, assinados em Nova York, em 30 de março de 2007. Diário Oficial da República Federativa do Brasil, Brasília, DF, n. 146, p. 3, 26 ago. 2009. Seção1.

Decreto n. 7.612, de 17 de novembro de 2011. Institui o Plano Nacional dos Direitos da Pessoa com Deficiência: Plano Viver sem Limite. Diário Oficial da República Federativa do Brasil, Brasília, DF, n. 221, p. 12, 18 nov. 2011. Seção 1.

. Lei n. 11.096, de 13 de janeiro de 2005. Institui o Programa Universidade para Todos (ProUni), regula a atuação de entidades beneficentes de assistência social no ensino superior; altera a Lei n. 10.891, de 9 de julho de 2004, e dá outras providências. 2005b. Diário Oficial da República Federativa do Brasil, Brasília, DF, n. 10, p. 7, 14 jan. 2005. Seção 1.

Lei n. 13.005, de 25 de junho de 2014. Aprova o Plano Nacional de

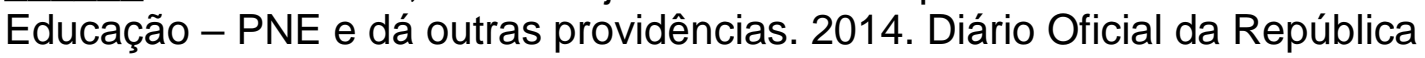
Federativa do Brasil, Brasília, DF, n. 120, p. 1, 26 jun. 2014. Seção 1. Edição Extra.

. Ministério da Educação. Parecer CNE/CEB n. 17/2001. Diretrizes Nacionais para a Educação Especial na Educação Básica. Diário Oficial da República Federativa do Brasil, Brasília, DF, n. 158, p. 46. 17 ago. 2001. Seção 1.

Portaria n. 14, de 24 abril de 2007. Dispõe sobre a criação do Programa Incluir: Acessibilidade na Educação Superior. 2007. Diário Oficial da República Federativa do Brasil, Brasília, DF, n. 80, p. 4, 26 abr. 2007. Seção 1.

Portaria n. 1.679, de 2 de dezembro de 1999. Dispõe sobre requisitos de acessibilidade de pessoas portadoras de deficiências, para instruir os processos de autorização e de reconhecimento de cursos, e de credenciamento de instituições. Diário Oficial da República Federativa do Brasil, Brasília, DF, n. 231, p. 20, 3 dez. 1999b. Seção 1.

Portaria n. 3.284, de 7 de novembro de 2003. Dispõe sobre requisitos de acessibilidade de pessoas portadoras de deficiência para instruir os processos de autorização e de reconhecimento de cursos e credenciamento de instituições. Diário Oficial da República Federativa do Brasil, Brasília, DF, n. 219 p. 12, 11 nov. 2003. Seção 1.

BUENO, J. G. S.. Deficiência e ensino superior: balanço das dissertações e teses brasileiras (1987/2006). In: CHICON, J. F.; DRAGO, R.; VICTOR, S. L. (Orgs.). A 
educação inclusiva de crianças, adolescentes, jovens e adultos: avanços e desafios. Vitória: Edufes, 2013.

CHARLOT, B. A pesquisa educacional entre conhecimentos, políticas e práticas: especificidades e desafios de uma área de saber. Revista Brasileira de Educação, v. 11, n. 31, p. 7-18, jan./abr. 2006. Disponível em:

<http://www.scielo.br/pdf/rbedu/v11n31/a02v11n31.pdf>. Acesso em: 18 mar. 2016.

DEMO, P. Cuidado metodológico: signo crucial da qualidade. Sociedade e Estado, v. 17, n. 2, dez. 2002. Disponível em: <http://dx.doi.org/10.1590/S010269922002000200007>. Acesso em: 15 abr. 2016.

DUARTE, A. Políticas educacionais e o trabalho docente na atualidade: tendências e contradições. In: DUARTE, A.; OLIVEIRA, D. A. Políticas públicas e educação: regulação e conhecimento. Belo Horizonte: Fino Traço, 2011.

DUARTE, E. R. et al. Estudo de caso sobre a inclusão de alunos com deficiência no ensino superior. Revista Brasileira de Educação Especial [online], v. 19, n. 2, 2013. Disponível em: $<$ http://www.scielo.br/scielo.php?script=sci_arttext\&pid=S141365382013000200011>. Acesso em: 20 mar. 2016.

FRANCO, M. L. P. B. Análise de conteúdo. 4. ed. Brasília: Líber Livro, 2012.

MANZINI, E. J.. Inclusão e acessibilidade. Revista da Sociedade Brasileira de Atividade Motora Adaptada, v. 10, n. 1, p. 31-36, dez. 2005. Disponível em: $<\mathrm{http}: / /$ www.rc.unesp.br/ib/efisica/sobama/vol10no1suplemento.pdf>. Acesso em: 5 abr. 2016.

Uso de entrevistas em um Programa de Pós-Graduação em Educação. Percurso, Maringá, v. 4, n. 2, p. 149-171, 2012. Disponível em: <http://periodicos.uem.br/ojs/index.php/Percurso/article/view/18577/10219>. Acesso em: 15 abr. 2016.

MARTINS, D. A.; LEITE, L. P.; LACERDA, C. B. F. de. Políticas públicas para acesso de pessoas com deficiência ao ensino superior brasileiro: uma análise de indicadores educacionais. Ensaio: Avaliação e Políticas Públicas em Educação, Rio de Janeiro, v. 23, n. 89, p. 984-1.014, out./dez. 2015. Disponível em: $<$ http://www.scielo.br/scielo.php?pid=S010440362015000400984\&script=sci_abstract>. Acesso em: 2 abr. 2016.

MAY, T. Pesquisa social: questões, métodos e processos. 3. ed. Porto Alegre: Artmed, 2004.

MOREIRA, L. C. In(ex)clusão na universidade: o aluno com necessidades educacionais especiais em questão. Educação Especial, Santa Maria, n. 25, p 3748, 2005a. Disponível em: <http://coralx.ufsm.br/revce/ceesp/2005/01/a3.htm >. Acesso em: 13 mar. 2016. 
. Retratos da prática avaliativa no contexto da sala de aula universitária com alunos com necessidades educacionais especiais. In: REUNIÃO ANUAL DA ASSOCIAÇÃO NACIONAL DE PÓS-GRADUAÇÃO E PESQUISA EM EDUCAÇÃO, 28., Caxambu, 2005. Anais... 2005b.

ORLANDO, R. M.; CAIADO, K. R. M. Professores universitários com deficiência: trajetória escolar e conquista profissional. Educação e Realidade, Porto Alegre, v. 39, n. 3, p. 811-830, jul./set. 2014. Disponível em:

<http://www.ufrgs.br/edu_realidade/>. Acesso em: 15 abr. 2016.

VALDÉS, M. T. M. (Org.). A Integração das Pessoas com Deficiência na Educação Superior no Brasil. Fortaleza: UECE, 2005.

VALDÉS, M. T. M. Inclusão de pessoas com deficiência no ensino superior no Brasil: caminhos e desafios. Fortaleza: Eduece, 2006. 